\title{
Análise de bibliografias antroposóficas de Rudolf Steiner por meio da metodologia de Benthall para religiões implícitas
}

\author{
Analysis of anthroposophic bibliographies by Rudolf Steiner \\ using the methodology of Benthal for implicit religions
}

\begin{abstract}
Fábio Leandro Stern
Doutorando em Ciência da Religião, PUC-SP, São Paulo, Brasil. Mestre em Ciência da Religião, PUC-SP, São Paulo, Brasil. Especialista lato sensu em Ciência da Religião, PUC-SP, São Paulo, Brasil. Membro do grupo de pesquisa em Novas Espiritualidades - NEO (PUC-SP). Bolsista da CAPES. Contato: caoihim@gmail.com
\end{abstract}

\author{
Bianca de Fiori Milani \\ Bacharela em Naturologia Aplicada, UNISUL, Palhoça, Brasil. Contato: biancamilani00@,hotmail.com
}

DOI: http://dx.doi.org/10.15517/rehmlac.v9i1.27667

Fecha de recibido: 15 de octubre de 2016 - Fecha de aceptación: 30 de enero de 2017

Palavras-chave

Antroposofia; Religião implícita; Pararreligião; Rudolf Steiner; Jonathan Benthall.

Keywords
Anthroposophy; Implicit religion; Parareligion; Rudolf Steiner; Jonathan Benthall.

\section{Resumo}

Esse trabalho tem como objetivo discutir a Antroposofia, que não se autoclassifica como uma forma de religião, mas que parece se adequar a algumas definições de religião e espiritualidade vigentes no campo da Ciência das Religiões. Por meio da metodologia de análise de Benthall, buscou-se verificar o quanto não seria a Antroposofia um objeto que nega sua dimensão religiosa, mas socialmente se comporta como algo religioso, o que a caracterizaria como uma religião implícita. Das dezenove categorias de análise, quinze foram encontradas, distribuídas nos livros pesquisados. Esse caso é um ilustrativo do recuo da influência da religião nas esferas culturais, podendo ser visto como uma possível busca por legitimação social frente a uma sociedade secular, que trata com desconfiança saberes oriundos do campo religioso.

\begin{abstract}
This paper aims to discuss anthroposophy, which does not consider itself as a form of religion, but seems to suit some definitions of religion and spirituality prevailing within the academic studies of religion. Using Benthall's methodology of analysis, it seeks to verify how far anthroposophy would deny its religious dimension, but nevertheless acts socially as a religion, which would characterize it as an implicit religion. Of the nineteen categories of analysis, fifteen were found distributed in the books we surveyed. This case is an example of the decline of the influence of religion in cultural spheres and can be seen as a possible pursuit for social legitimacy in response to a secular society, which treats knowledge derived from religious fields with suspicion.
\end{abstract}




\section{Introdução}

Oriunda do esoterismo europeu do século XIX, a Antroposofia vem ganhando abrangência em diversas áreas de estudos e atuações no Brasil e no mundo. Pressupondo englobar pensamentos científicos, políticos, artísticos e espirituais em uma unidade que busca proporcionar respostas e realizações das questões mais profundas da humanidade, seu espaço de atuação vai além do conhecimento material, adentrando em um campo metaempírico.

Dentre os diversos contextos com os quais dialoga, uma das áreas que adentra é a religião. Embora atribuam uma perspectiva espiritual ao seu trabalho, entretanto, é comum aos praticantes da Antroposofia lhe negarem uma dimensão religiosa, lutando para não a assumir como um tipo de religião. Citando como exemplo uma fala interna:

Não, a Antroposofia não é uma religião, nem é talhada para ser um substituto para a religião. Enquanto seus conhecimentos podem apoiar, iluminar ou complementar a prática religiosa, ela não fornece qualquer sistema de crenças. A Sociedade Antroposófica é aberta a pessoas de qualquer fé, como também àqueles que não aderem a uma fé particular ${ }^{1}$.

Essa recusa pode acontecer por diversos motivos, sendo o mais provável um entendimento estrito do que é religião. Para o antroposófico Setzer², a Antroposofia não se encaixa no perfil de uma religião por não ter cultos públicos, sendo cultivada individualmente, possuindo no máximo grupos de estudos nas diversas instituições onde é notada. Porém, essa interpretação do que é uma religião é rapidamente problematizada se levarmos em conta o conhecimento acadêmico produzido sobre o tema.

Embora possua uma dimensão coletiva, nem toda religião é voltada para rituais públicos. As religiões eclesiais, organizadas em instituições e hierarquias públicas, são apenas um dos tipos possíveis de como as religiões podem se manifestar. Outros tipos englobam religiões declaradamente individualistas, das quais seriam exemplos vários esoterismos e religiões da Nova Era, assim como as religiões xamânicas, pautadas na jornada visionária interior, que é uma experiência religiosa singular ${ }^{3}$.

Rudolf Steiner, o criador da Antroposofia, também enfatiza uma identidade não religiosa, articulando que a Antroposofia não objetiva suprimir qualquer crença, não sendo sua incumbência a formação de um sistema religioso próprio. Ao contrário, para Steiner a Antroposofia pressupõe um diálogo calcado na harmonia das crenças.

\footnotetext{
${ }^{1}$ Jean Yeager, “Is Antroposophy a Religion?", em Waldorf Answer (2004-2014 [acesso em 12 de março de 2016]): http://www.waldorfanswers.org/NotReligion1.htm

2 Valdemar W. Setzer, “O que é Antroposofia" (1999 [acesso em 19 de abril de 2016]): http://www.sab.org.br/antrop/ANmainFrame.htm

${ }^{3}$ Anthony F. C. Wallace, Religion: an Anthropological View (New York: Random House, 1966).
} 
[...] ela não intervirá em qualquer credo religioso, na esfera de qualquer tipo de vida religiosa [...] A Ciência Espiritual jamais pode desejar criar uma religião [...] Não se pode, assim, chamar de fé religiosa a Ciência Espiritual como tal. Ela não visa criar uma fé religiosa, nem mudar, de qualquer forma, alguém em relação às suas crenças religiosas [...] porque na Sociedade Antroposófica todo tipo de religião está representado, e não há nada que impeça qualquer um de exercer sua fé religiosa plenamente, de modo amplo e intensivo, como desejar ${ }^{4}$.

Mas esse argumento também não é suficiente. A múltipla pertença religiosa é cada vez mais comum na modernidade, acompanhada usualmente de uma recusa a sistemas tradicionais institucionalizados de religião. Mas nem por isso esses novos arranjos não são religiosos. Citando o exemplo da profusão de espiritualidades que surgiu com o movimento da Nova Era, em meados do século XX, seus adeptos são caracterizados justamente por apresentarem grande fluidez de pertença religiosa ${ }^{5}$.

Assim, embora internamente os antroposóficos declarem que suas práticas não são religiosas, pelo menos academicamente a Antroposofia tem sido descrita como algo que se comporta de forma muito parecida com uma religião. Sua ruptura com a Teosofia se deu por divergências teológicas (uma maior identificação com o cristianismo em contrapartida à maior identificação com o budismo e hinduísmo pelos teosóficos), e assim como ocorre na Teosofia, os propósitos antroposóficos visam à conexão com uma dimensão interna, que se abre através da vivência espiritual, o que faz com que seus adeptos sejam muito empenhados em formas alternativas de religiosidade. Por esse motivo, Staudenmaier ${ }^{6}$ comenta que academicamente a Antroposofia não é considerada uma "ciência", como seus adeptos lhe descrevem, mas uma variante do esoterismo europeu, fusionada por diversas correntes esotéricas.

Citando alguns exemplos, Tolcheva ${ }^{7}$ apresenta a Antroposofia justamente como um sincretismo religioso centrado em uma forma particular de esoterismo cristão. Um artigo clássico $^{8}$, publicado ainda em 1924 no The Journal of Religions da Universidade de Chicago, já apresentava a Antroposofia como uma nova forma de Teosofia. Posteriormente Pasi $^{9}$ identificou que a Teosofia, ao menos na Itália, apresentava maiores relações com a Maçonaria que a Antroposofia, ainda que ambas compartilhassem um mesmo histórico de

\footnotetext{
${ }^{4}$ Gunter Wachsmuth ed., The Life and Work of Rudolf Steiner: From the Turn of the Century to his Death (New York: Whittler, 1955), 100-101 [tradução nossa].

${ }^{5}$ Wouter J. Hanegraaff, New Age Religion and Western Culture: Esotericism in the Mirror of Secular Thought (Leiden: Brill, 1996), 13-18.

${ }^{6}$ Peter Staudenmaier, Between Occultism and Nazism: Anthroposophy and the Politics of Race in the Fascist Era (Leiden: Brill, 2014), 2.

7 Svetoslava Toncheva, “Antroposophy as Religious Syncretism”, SOTER: Journal of Religious Science XLVIII (2013): 84.

${ }^{8}$ Carl Clemen, “Anthroposophy”, The Journal of Religion IV, no. 3 (1924): 281-292.

9 Marco Pasi, "Theosophy and Anthroposophy in Italy during the First Half of the Twentieth Century", Theosophical History: A Quartely Journal of Research XVI, no. 2 (2012): 81-119.
} 
influências maçônicas. A respeito da autodefinição da Antroposofia como Ciência Espiritual, Leijenhorst ${ }^{10}$ comenta que essa suposta ciência era descrita por seu próprio criador como algo que conecta a dimensão espiritual do ser humano com a dimensão espiritual do cosmo -o que se parece muito mais com a descrição de algo religioso do que de algo científico. Por fim, ao listar as diferentes aplicabilidades da Antroposofia contemporânea (saúde holística, pedagogia alternativa, agricultura orgânica, consciência ambiental etc.), Staudenmaier ${ }^{11}$ descreve esforços em formas inovadoras de expressão espiritual pelos antroposóficos.

$\mathrm{O}$ fato é que cresce o número de manifestações sociais que, assim como a Antroposofia, não se reconhecerem como religiosas, mas que poderiam ser classificadas dessa forma pelos acadêmicos. Na Ciência das Religiões, esses casos são chamados de religiões implícitas, nomenclatura cunhada na década de 1960 por Edward Baley, e que desde então passou a englobar uma constelação de termos próximos (p. ex. "quasirreligião", "pseudorreligião", "pararreligião"), que se referem aos elementos ou função religiosa em coisas que, usualmente, não são consideradas religiosas ${ }^{12}$.

Até recentemente havia uma carência de metodologias padronizadas para se trabalhar com essa categoria. Então Jonathan Benthall reestruturou, na década de 2000, uma forma de análise metodológica para religiões implícitas, criando categorias que podem ser aplicadas aos objetos que se suspeita serem religiosos, mas que não se admitem religiosos, ampliando o conceito para caracterizar as diversas roupagens que nele se conceitua e se encontrariam as religiões implícitas.

Como a assimilação de um conceito pode se diferenciar segundo o prisma analisado, torna-se imprescindível discernir o sujeito por trás da lente, para que um trabalho hermenêutico mais acurado aconteça. A este propósito Hanegraaff ${ }^{13}$ escreve que "a principal ferramenta teórica para salvaguardar a legitimidade científica nesta situação é a distinção entre êmico e ético". O discurso êmico denota os padrões intersubjetivos de pensamento e simbolismo do fiel, o ponto de vista de quem crê. Mas aos eruditos, as construções devem se pautar no discurso ético, uma interpretação da religião a partir das categorias de análise (sociológicas, historiográficas, antropológicas, psicológicas) daqueles que os observam, perpassando pelo crivo de quem analisa. Ou seja, a visão do cientista social, do "eu em direção ao outro".

Por parte do pesquisador, é requerida uma atitude empática à perspectiva êmica. Contudo, os resultados finais da investigação devem ser expressos pelo discurso ético.

\footnotetext{
${ }^{10}$ Cees Leijenhorst, “Anthroposophy”, in Dictionary of Gnosis \& Western Esotericism, ed. Wouter J. Hanegraaff (Leiden: Brill, 2006), 82.

${ }^{11}$ Staudenmaier, Between Occultism and Nazism, 1.

12 Arnaldo Nesti, "Implicit Religion", in Encyclopedia of Religion, ed. Lindsay Jones (Farmington: Thomson Gale, 2005), 4400.

${ }^{13}$ Hanegraaff, New Age Religion and Western Culture, 6 [tradução nossa].
} 
Ressalta-se que não concerne ao cientista das religiões julgar a veracidade do discurso êmico. Pelo contrário, é adotado como pressuposto o agnosticismo metodológico. "Comprometido com esse ideal, o cientista da religião exclui da sua agenda a questão da "última verdade",14, não negando nem se preocupando com essa dimensão, mas se limitando às questões humanas e possíveis de serem estudadas materialmente.

Pelo postulado da visão êmica e ética, talvez a Antroposofia seja um exemplo de um grupo que eticamente poderia ser classificado como religioso, mas cujo discurso êmico não assume plenamente sua identidade religiosa. Para investigar isso, obras êmicas do criador da Antroposofia serão analisadas, através do instrumental ético das religiões implícitas apresentado nos Materiais e Métodos.

\section{Antroposofia}

A Antroposofia é uma escola esotérica dissidente da Teosofia criada por Rudolf Joseph Lorenz Steiner (1861-1925), educador-esotérico austríaco que pregava que seus ensinamentos eram um "antídoto" ao materialismo da modernidade ${ }^{15}$. Steiner declarava que seus estudos abrangiam um campo que ele chamava de "Ciência Espiritual" (com letra maiúscula), e suas vivências, as quais ele tratava como "pesquisas", eram de caráter contemplativo, visando apreciar o mundo oculto do espírito ${ }^{16}$.

Após se mudar para Berlim, Steiner se juntou à Sociedade Teosófica em 1902, tornando-se rapidamente secretário geral, posição que manteve por uma década ${ }^{17}$. Posteriormente, por divergências teológicas acerca do retorno de Cristo - que para ele seria algo "etérico", não material ${ }^{18}$-, Steiner rompeu com a Sociedade Teosófica, levando diversos membros consigo. A partir disso, Steiner militou fortemente para que a Antroposofia não fosse identificada como um sinônimo de Teosofia (o que Clemen ${ }^{19}$ considerou como insuficiente, visto que para ele a Antroposofia não é tão independente e diferente assim da Teosofia quanto Steiner declarava).

Steiner proferiu mais de 5.900 palestras difundindo a Antroposofia pela Europa, dispondo de um vasto compêndio de conferências e livros cujos originais podem ser encontrados em Goetheanum, a sede mundial da Antroposofia em Dornach, na Suíça. Segundo Leijenhorst ${ }^{20}$, a influência do cristianismo é evidente em muitas ideias de Steiner,

\footnotetext{
${ }^{14}$ Frank Usarski, "História da Ciência da Religião", Ciberteologia: Revista de Religião e Cultura X, no. 47 (2014): 139.

${ }^{15}$ Leijenhorst. “Anthroposophy”, 82.

${ }^{16}$ Robert A. McDermott, “Anthroposophy”, in Encyclopedia of Religion, ed. Lindsay Jones (Farmington: Thomson Gale, 2005), 392.

${ }^{17}$ Staudenmaier, Between Occultism and Nazism, 1.

${ }^{18}$ Toncheva, “Antroposophy as Religious Syncretism”, 84.

${ }^{19}$ Clemen, "Anthroposophy”, 281.

${ }^{20}$ Leijenhorst, "Anthroposophy”, 84.
} 
com destaque à reivindicação de que a Antroposofia seria capaz de preparar seus adeptos à chegada de Cristo no século XX. Para Steiner, Cristo era essencialmente o logos divino encarnado, o "espírito do sol” que desceu para resgatar não só a humanidade, mas também o próprio planeta. Para ele, a humanidade sucumbiu às forças do mal, o que teria tornado seus corpos mortais e decadentes. Para revitalizar a humanidade, Cristo teve que provar a morte e fazer o sacrifício final, tornando-se o "sol interior", o espírito da Terra, restaurando seu sentido e finalidade.

Além da "cristologia", outra ideia fundamental à Antroposofia é a "fisiologia oculta", categoria êmica que se refere à concepção antroposófica de corpo. A físiologia oculta declara que os humanos são divididos em vários corpos que corresponderiam a véus de consciência. Conhecer o mundo espiritual seria o mesmo que desvelar esses véus, imergindo no que Steiner chama de "eu" (self). Os humanos seriam constituídos por três corpos principais - o corpo físico, corpo etérico e corpo astral -, com um corpo extra, o "eu" (self), formando, assim, o conceito de "quadrimembração". O corpo físico é a camada exterior, mais densa e tangível, que contém a impressão do tempo findável das leis orgânicas, visto morrer. É através dele que são recebidas as percepções sensoriais. O corpo etérico, ou corpo vital, abrange as funções orgânicas básicas, como a respiração, regeneração, os processos bioquímicos e a reprodução. O corpo astral, também chamado de corpo anímico ou alma, rege as forças da consciência responsáveis pela vida sensitiva, organizando os processos vitais. É o agente dos comportamentos, desejos, paixões, simpatias e antipatias, desde os instintos mais primitivos até os sentimentos mais nobres e sublimes. Por fim o "eu" (self), também chamado de espírito, seria a verdadeira entidade, e os outros corpos seriam apenas invólucros dentro dos quais o "eu" vive a essência espiritual humana ${ }^{21}$.

Com o objetivo de atingir todos os corpos, caminhando em direção à libertação do "eu", Steiner se focou na multiplicidade do cultivo do conhecimento imaginativo pela transposição do mundo natural com o desenvolvimento humano, o conhecimento intuitivo e a inspiração advinda do espírito que, acreditava ele, levaria ao contato com o "eu". Para isso, conduziu pesquisas esotéricas sobre os mistérios da vida, da morte e do renascimento. Estudou grandes mestres espirituais, como Moisés, Zoroastro, Kṛ̣ṇa, Buda e São Francisco, e o papel deles na evolução da consciência humana. Considerava também grandes filósofos, como Platão e Sócrates, igualmente mestres por sua contribuição à evolução do pensamento humano. Por fim, ao compilar seus achados, Steiner registrou seu método esotérico, que posteriormente foi aplicado à medicina, à pedagogia, à agricultura, à música, à dança e à economia, esboçando tentativas de unificar a consciência material e espiritual dos antroposóficos ${ }^{22}$.

\footnotetext{
${ }^{21}$ Leijenhorst, "Anthroposophy", 81-84.

${ }^{22}$ McDermott, “Anthroposophy”, 392-393.
} 


\section{Definindo religião}

Um grande desafio a cientistas das religiões é definir o que é religião. Já no início do século XX poderiam ser encontradas mais de cinquenta definições acadêmicas diferentes $^{23}$. Desde então, esse número apenas cresceu, em especial após a explosão dos novos movimentos religiosos posteriores à Segunda Guerra Mundial, gerando a necessidade dos especialistas entenderem as religiões nessa nova pluralidade.

O desafio abrange um amplo leque de descrições que vêm se modificando pelo tempo e espaço. Até 1970, por exemplo, foi muito popular na Europa uma aproximação aberta ao objeto, conforme feito por Mircea Eliade ${ }^{24}$, uma das maiores referências mundiais na história da Ciência das Religiões. Mas se por lá o uso da abordagem eliadiana caiu consideravelmente em desuso, no Brasil ela continua muito popular à maioria dos cientistas das religiões ${ }^{25}$, demonstrando a variação espacial do conceito.

Além do tempo e do espaço, a perspectiva do narrador também deve ser considerada. Hanegraaff considera que essas três dimensões são o que estabelecem um entendimento do que é religião ${ }^{26}$. E insatisfeito com os conceitos até então existentes, apresentou uma definição tríplice própria, dividida em (1) religião (geral), (2) uma religião (específica), e (3) espiritualidade ${ }^{27}$, que evidencia uma singularidade teorética.

Segundo Hanegraaff, religião (geral) abrange

[...] qualquer sistema simbólico que influencie as ações humanas, fornecendo possibilidades para manter contato ritualisticamente entre o mundo cotidiano e um quadro metaempírico mais geral de significados ${ }^{28}$.

Essa definição sintetiza praticamente todo conceito que alguém pode formular sobre religião intuitivamente, sem tornar seu entendimento vago ou trivial. Não exclui sistemas simbólicos incorporados em instituições sociais, como as igrejas tradicionais, nem o fenômeno contemporâneo de sistemas simbólicos de organizações privadas.

\footnotetext{
${ }^{23}$ Klaus Hock, Introdução à Ciência da Religião (São Paulo: Loyola, 2010), 17.

${ }^{24}$ Eliade nunca desenvolveu uma definição de religião em si, mas se preocupou hermeneuticamente em entender a "experiência religiosa" do Homo religiosus, que se presume a algo sui generis (o Sagrado), único, universal e trans-histórico, que se "manifestaria" independentemente do contexto sócio-histórico. Cruz ("Estatuto epistemológico da Ciência da Religião", 72) comenta que a principal crítica recebida a essa abordagem é seu caráter criptoteológico (teologia disfarçada de ciência), visto que boa parte da produção derivada dela é composta por discursos secularizados de uma teologia protestante liberal.

${ }^{25}$ Eduardo R. Cruz, "Estatuto epistemológico da Ciência da Religião", Ciberteologia: Revista de Religião e Cultura X, no. 47 (2014): 70-72, 76-77.

${ }^{26}$ Wouter J. Hanegraaff, "Defining religion in spite of History", in The Pragmatics of Defining Religion: Contexts, Concepts \& Contests, ed. Jan G. Platvoet and Arie L. Molendijk (Leiden: Brill, 1999), 337-341.

${ }^{27}$ Hanegraaff, "Defining religion in spite of History", 371-373.

${ }^{28}$ Hanegraaff, "Defining religion in spite of History", 371 [tradução nossa].
} 
Mas conforme a religião (geral) se insere nas sociedades, adquire formas microssociais e macrossociais distintas, tornando-se uma religião (específica), ou seja, [...] um sistema simbólico, incorporado em uma instituição social, que influencia as ações humanas, oferecendo possibilidades para manter contato ritualisticamente entre o mundo cotidiano e um quadro metaempírico mais geral de significados ${ }^{29}$.

A diferença entre religião (geral) e uma religião (específica) é que a ultima tem uma representação nominal reconhecida pela sociedade, usualmente tem características sectárias (nós e eles), congregações, posições hierárquicas, e são, em maior ou menor grau, organizadas ao redor de uma figura social institucionalizada. A religião (específica) é justamente a institucionalização social da religião (geral), na qual os adeptos se reúnem através de sua instituição.

Porém, existem sujeitos religiosos, no sentido de religião (geral), que não se integram em uma manifestação social, uma religião (específica). São os "religiosos sem religião", "espiritualizados", que não possuem uma confissão clara, mas que seria errôneo não serem considerados como religiosos. Para esses, Hanegraaff apresenta a categoria espiritualidade: [...] qualquer prática humana que mantenha o contato entre o mundo cotidiano e um quadro metaempírico mais geral de significados por meio da manipulação individual dos sistemas simbólicos ${ }^{30}$.

Esse conceito abrange a prática dentro da individualidade das relações que uma pessoa exerce em seu cotidiano, buscando um significado à vida mundana através de um sistema simbólico - que pode ser uma religião (específica). Uma religião (específica) é um constructo social, comunitário. O sujeito não é a comunidade, mas um componente dela, trazendo consigo suas vivências e diferenças, que são incorporadas a partir de uma biografia única. Por essa singularidade vivencial o sujeito engendra em sua crença idiossincrasias, modificando determinados conceitos religiosos pré-estabelecidos segundo sua congruência. Em suma, ninguém possui uma religião (específica), mas uma espiritualidade com base em uma (ou mais) religião (específica).

Pelas premissas apresentadas, a Antroposofia seria religião, ainda que não se reconheça como tal. Tanto o conceito hanegraffiano de religião (geral) quanto de uma religião (específica) lhe são aplicáveis. A Antroposofia se apresenta como um sistema simbólico que conduz à conexão de um campo não empírico, espiritual. E como possui nome, fundador, escolas, gráficas, editoras, sociedades, sede mundial e muitas formas de institucionalização, ela também pode ser classificada como uma religião (específica).

\footnotetext{
${ }^{29}$ Hanegraaff, "Defining religion in spite of History", 372 [tradução nossa, grifo nosso].

${ }^{30}$ Hanegraaff, "Defining religion in spite of History", 372 [tradução nossa].
} 


\section{Materiais e Métodos}

Pelos critérios de $\mathrm{Gil}^{31}$, essa é uma pesquisa bibliográfica e documental, de enfoque qualitativo e objetivo descritivo. Para garantir uma representatividade adequada da Antroposofia, focamo-nos apenas nas obras de seu criador, Rudolf Steiner, lançadas em português pela editora Antroposófica. Como o volume de obras que se encaixavam nesses critérios era superior a 200, elencamos apenas os livros presentes na bibliografia básica para entender a Antroposofia segundo a Associação de Pedagogia Social, órgão fundado em 1974 no Brasil que visa difundir a pedagogia antroposófica no país.

Os nove livros listados no site da Associação de Pedagogia Social eram:

- O conhecimento dos mundos superiores ${ }^{32}$ : obra que propõe desvelar o caminho para a espiritualidade esotérica através de rituais de observação da natureza, transpondo o conhecimento natural à vida cotidiana. Dentre os temas abordados, fala sobre o conhecimento dos mundos superiores, sua relação com a vida e a morte, os graus da iniciação esotérica e o papel dos sonhos nesse processo.

- A educação prática do pensamento $^{33}$ : Transcrição de uma palestra de Steiner, proferida na Alemanha em 1909. Explica como as práticas de observação da natureza devem ser feitas e transpostas ao cotidiano, para se assimilar a verdadeira natureza da natureza. É dado grande enfoque à prática do pensamento, que pressupõe atitude correta e sentimento adequado. Suas considerações sobre o ato de pensar se aproximam da visão neoplatônica que estava em voga no século XIX.

- Economia e sociedade à luz da Ciência Espiritual ${ }^{34}$ : Esse livro discute como seria a economia e uma sociedade ideal, pautada em ensinamentos antroposóficos. Contém proposições de alternativas tanto ao capitalismo quanto ao socialismo, em especial aos supostos malefícios que esses dois sistemas causam à humanidade.

- Economia viva ${ }^{35}$ : Essa obra descreve o dinheiro como algo bom, fazendo uma alegoria entre a fluidez econômica e a corrente sanguínea. Para Steiner, o mundo é um organismo vivo, descrito nesse livro como um organismo econômico.

\footnotetext{
${ }^{31}$ Antonio Carlos Gil, Métodos e técnicas de pesquisa social (São Paulo: Atlas, 2008).

${ }^{32}$ Rudolf Steiner, $O$ conhecimento dos mundos superiores (São Paulo: Antroposófica, 2011).

${ }^{33}$ Steiner, A educação prática do pensamento: aprender a pensar a partir da realidade (São Paulo: Antroposófica, 2010).

${ }^{34}$ Steiner, Economia e sociedade à luz da Ciência Espiritual (São Paulo: Antroposófica, 2007).

${ }^{35}$ Steiner, Economia viva: o mundo como organismo econômico único (São Paulo: Antroposófica, 2006).
} 
- O anjo em nosso corpo astral ${ }^{36}$ : A maior ênfase dessa obra está na busca pelo caminho da liberdade e o papel dos humanos na hierarquia de seres angelicais. Duas influências principais são trabalhadas: as energias luciféricas, que promovem a desconexão com o mundo material, e as energias de Árimã, que promovem o oposto. Nessa perspectiva, as energias crísticas se apresentariam como o caminho do meio, proporcionando o verdadeiro despertar do livre arbítrio.

- A missão das almas dos povos ${ }^{37}$ : Reunião de transcrições de três conferências, ocorridas em 1910, nas quais é apresentada a ideia de que cada nação, raça, povo ou país é regido por uma entidade espiritual, uma alma que, através de suas influências sobre as sociedades, evolui em conjunto com os povos que rege.

- Teosofia ${ }^{38}$ : Livro original de 1904 que apresenta a Teosofia, descrevendo-a como a base para se entender a Antroposofia. Embora a Teosofia seja a origem histórica da Antroposofia, uma relação direta de "parentesco" não é estabelecida na obra.

- Filosofia da liberdade ${ }^{39}$ : Ensaio filosófico original de 1894 sobre o pensar pela óptica esotérica, que posteriormente seria incorporada pela Antroposofia. Nessa obra, Steiner dialoga com diversos autores da Filosofia, elucidando através deles sua noção de liberdade, pensamento, sentimento e ação consciente.

- A Ciência Oculta: esboço de uma cosmovisão suprassensorial ${ }^{40}$ : O subtítulo dessa obra resume sua proposta principal. Nela, uma narrativa da evolução humana é apresentada, perpassando noções de passado, presente e futuro da evolução cósmica humana. É uma das obras mais completas da lista, abordando desde a expansão da consciência até o lugar do ser humano no mundo espiritual.

A análise foi realizada simultaneamente com a coleta de dados, utilizando-se da metodologia de Benthall ${ }^{41}$. Esse método é pautado em 19 categorias de análise que representam dimensões de como as religiões se manifestam. Quanto mais dessas categorias um objeto apresentar, mais religioso ele seria. Sobre o método, Benthall escreve: “[...] tento

\footnotetext{
${ }^{36}$ Steiner, $O$ anjo em nosso corpo astral: como eu encontro Cristo? (São Paulo: Antroposófica, 2008).

${ }^{37}$ Steiner, A missão das almas dos povos (São Paulo: Antroposófica, 2014).

${ }^{38}$ Steiner, Teosofia: introdução ao conhecimento supra-sensivel do mundo e do destino humano (São Paulo: Antroposófica, 1994).

39 Steiner, Filosofia da liberdade: fundamentos para uma filosofia moderna (São Paulo: Antroposófica, 2008).

${ }^{40}$ Steiner, A ciência oculta: esboço de uma cosmovisão supra-sensorial (São Paulo: Antroposófica, 2001).

${ }^{41}$ Jonathan Benthall, Returning to religion: why a secular age is haunted by faith (London: I. B. Tauris, 2008).
} 
usá-lo com estrita neutralidade, para significar movimentos ou instituições que têm algumas, mas não todas, as características de religiões em um sentido mais estrito" ${ }^{42}$. Isso significa que um objeto não precisa apresentar todas as categorias para ser considerado uma religião implícita.

Finalmente, deve-se atentar que Benthall têm como propósito uma reflexão sobre até que ponto um objeto que não se diz religioso parece ou se comporta como tal, e que não é preocupação de seu método o esgotamento da significação literal de cada categoria. Isso se dá porque, conforme citamos anteriormente, existe uma polissemia muito grande a respeito do que é religião; e por pressuposto, do que é religioso.

Cada categoria será explicada a seguir, conforme as análises dos dados nos resultados e discussões forem apresentadas.

\section{Resultados e Discussões}

Foram encontradas 15 das 19 categorias distribuídas nos livros pesquisados. Três categorias - (1) apelo ao metaempírico, (2) explicação do lugar do ser humano no mundo e (3) crença/discursos totalizantes - foram encontradas em todas as obras. As outras 13 categorias foram observadas em pelo menos um dos livros elencados.

A seguir apresentaremos cada categoria, elencando algumas citações que corroboram com os indícios de que a Antroposofia seria uma religião implícita, de acordo com o referencial metodológico adotado.

\section{Apelo ao metaempirico}

A primeira categoria diz respeito à suposição comum às religiões da existência de coisas que estão além das sensações. Espíritos, divindades, santos, outros corpos, outras realidades/dimensões... tudo isso que não pode ser aferido pelos cinco sentidos.

Todas as obras possuem esse apelo. O discurso antroposófico diz que os cinco sentidos captam apenas uma fração da multidimensionalidade. A dimensão física é apenas um aspecto manifesto do "eu" total. O "descortinar" dos "véus do espírito", visando transcender o material, dar-se-ia através de um elevado trabalho para unir o "eu" total àquilo que é o "espírito oculto", algo metaempírico. Essa transformação gradual ocorre por um conhecimento superior que transcende os limites da consciência empírica, conduzindo ao despertar de faculdades latentes de natureza espiritual.

Destacando algumas citações da literatura analisada, em Teosofia Steiner fala sobre "[...] coisas que manifestamente transcendem a faculdade cognitiva humana"43. No livro $A$ missão da alma dos povos há também uma passagem que aborda "[...] a noção da existência

\footnotetext{
${ }^{42}$ Benthall, Returning to religion, 11.

${ }^{43}$ Steiner, Teosofia, 21.
} 
de entidades que não se apresentam ao poder de percepção material ordinário e não se expressam na esfera sensorial" "44. Essas transcrições se encaixam exatamente no que é entendido por metaempírico segundo Benthall ${ }^{45}$.

Por fim, em $O$ anjo em nosso corpo astral há uma passagem na qual Steiner explica que "o homem se compõe - em sentido descendente - do eu, do corpo astral, do corpo etérico [...] e do corpo físico" "46. Os corpos astral, etérico e o próprio eu (self) não podem ser captados ou percebidos somente pelos cinco sentidos comuns.

\section{Apelo ao mundo utópico}

Muitas religiões almejam um ideal de mundo sublime, melhor que esse mundo imediato, onde a plenitude reina. Esse ideal pode ter existido em um passado mítico ou refletir um anseio futuro de realização espiritual. Algumas religiões tratam esse mundo como um estado de espírito, e outras falam de utopias para além do espaço-tempo. De qualquer modo, seja transcendente (p. ex. paraíso bíblico) ou imanente (p. ex. promover a utopia na terra através de atitudes humanitárias), o apelo a esse mundo segue como um fator importante para se considerar um objeto religioso 47 .

Foram encontrados indícios de apelo ao mundo utópico em A Ciência Oculta, Economia viva, Filosofia da liberdade, A missão da alma dos povos, Economia e sociedade à luz da Ciência Espiritual, $O$ anjo em nosso corpo astral e $O$ conhecimento dos mundos superiores. Segundo a visão êmica antroposófica, a senda espiritual conduz ao mundo suprassensível, que é o mundo total, ao contrário do mundo físico, cujas percepções são ilusórias, frações da realidade. Ao percorrer o caminho existencial da vida espiritual, o antroposófico desvendaria essa realidade, que a princípio está oculta.

Para a Antroposofia, Jesus é um exemplo de homem ideal, o reconhecimento da centelha divina que nos une na matéria. Em A Ciência Oculta, Steiner comenta que "ao lado de todos os antepassados terrestres aparece o Pai comum a todos os homens. Eu e o Pai somos Um"48, fazendo uma alegoria entre Cristo e toda a raça humana.

Em $O$ conhecimento dos mundos superiores é encontrada a seguinte passagem:

Algo começa, a partir do silêncio, a falar-lhe. Antes, só lhe ressoava através de seus ouvidos; agora, ressoa através de sua alma. Descortina-se uma língua interior - um verbo interior. O discípulo sente-se enlevado ao máximo quando, pela primeira vez, vivência esse momento. Sobre todo o seu mundo exterior derrama-se um luz

\footnotetext{
${ }^{44}$ Steiner, A missão das almas dos povos, 3 .

${ }^{45}$ Benthall, Returning to religion, 22-24.

${ }^{46}$ Steiner, $O$ anjo em nosso corpo astral, 11.

${ }^{47}$ Benthall, Returning to religion, 24-25.

${ }^{48}$ Steiner, A ciência oculta, 213.
} 
interior. Uma segunda existência começa para ele. A corrente de um mundo divino, divinamente sublime, derrama-se através dele ${ }^{49}$.

A crença contida essa citação é de que o sujeito, em seu silêncio contemplativo, receberá do seu âmago, seu "eu" (self), vozes vindas do mundo espiritual, um mundo inefável, onde seus sentimentos e ocupações cotidianas nada podem dizer. Acredita-se que esse mundo seria mais alcançável pelo sentimento pleno da alma Divina.

\section{Crenças/discursos totalizante}

A categoria crenças/discursos totalizantes diz respeito à convicção das religiões de que suas explicações contemplam toda a realidade humana, independente do tempo e do espaço, sendo eternas e transculturais. Tem como exemplo o literalismo bíblico, que desconsidera a localização histórica e mudanças sociais ao longo do escrito, alegando atemporalidade aos dogmas bíblicos, que seriam aplicáveis a qualquer cultura e época ${ }^{50}$.

Foram encontrados discurso totalizante em todas as obras analisadas. O mais evidente é a universalidade da busca pela libertação do "eu" (self), considerada como algo cabível a todos, independente do lugar, época ou crenças.

Destacando uma citação:

[...] no fundo toda e qualquer aspiração cultural da humanidade se baseia na superação dessa contraposição [entre o "eu” e o mundo]. A história cultural é, pois, o resultado da incessante busca pela unidade entre o eu e o mundo. Religião, Arte e Ciência procuram, cada uma a seu modo, esse mesmo fim ${ }^{51}$.

Segundo Steiner, a busca por sentido pessoal, que inicia quando a consciência tem seu primeiro despertar, representa um descontentamento traduzido no sectarismo entre o "eu" e o mundo. Porém para ele não existe um ente fora, mas uma malha unida em um mesmo pulsar melódico. O discurso é totalizante porque Steiner considera toda a aspiração cultural humana se baseia nessa busca de comunhão com o universo.

Outra passagem que se encaixa nessa categoria:

Acontece que os ensinamentos da Ciência Espiritual são as verdadeiras leis da vida, da mesma forma como o são os ensinamentos da eletricidade para uma fábrica de aparelhos elétricos. Quem deseja instalar uma fábrica deve, primeiro, adquirir os conhecimentos da eletricidade; e quem quer atuar na vida deve conhecer suas leis ${ }^{52}$.

\footnotetext{
${ }^{49}$ Steiner, O conhecimento dos mundos superiores, 29.

${ }^{50}$ Benthall, Returning to religion, 26-28.

${ }^{51}$ Steiner, Filosofia da liberdade, 8.

${ }^{52}$ Steiner, Economia e sociedade à luz da Ciência Espiritual, 16-17.
} 
Se para atuar na vida é necessário conhecer a Ciência Espiritual, então todos precisam estar a par de seus ensinamentos. Esse exemplo parte do pressuposto claro de uma transculturalidade para o saber antroposófico.

\section{Explicação do lugar do ser humano no mundo}

Toda religião se preocupa com a questão existencial humana. Quem somos nós? Onde nos encaixamos no universo? Existe algo além do que conhecemos? A busca por uma explicação pode se manifestar na criação e manutenção de significados diversos que corroboram noções de progresso e propósito de vida ${ }^{53}$.

Foram encontrados indícios dessa categoria em todas as obras. A Ciência Oculta apresenta a crença de que a humanidade é povoada por entidades de diversos mundos, que encarnaram primeiramente nos descendentes do continente lendário de Lemúria. As várias raças seriam consequências disso, e cada alma reencarnada surge em resposta a seu carma individual, advindo de seu mundo de origem. Nosso objetivo seria descobrir a "natureza espiritual" das coisas, promovendo a evolução espiritual da humanidade.

Em A missão da alma dos povos é dito que ao atingir determinado nível de evolução espiritual, os indivíduos perdem seus corpos inferiores (físico, etérico e astral), transmutando em personalidade espiritual pura. Em Filosofia da liberdade essa visão é complementada, dizendo que a menos que assumamos as rédeas de nosso destino, a humanidade permanecerá latente no mundo dos corpos inferiores. É esboçada uma noção de liberdade em oposição à natureza e à sociedade, na qual o humano social é um autômato que opera conforme leis morais impostas pela comunidade, e o humano natural está fadado às leis da natureza. O objetivo, segundo a obra, é transcender ambas, e se tornar um ser totalmente liberto e espiritual.

\section{Narrativa de fundação}

Praticamente toda religião possui uma lenda, mito ou história de criação de sua doutrina, descrita de modo a enaltecer o fundador (ou o próprio ato da fundação) do grupo $^{54}$. Contudo, sendo o fundador da Antroposofia o próprio Steiner, o autor das obras aqui analisadas, não foram encontrados indícios concretos dessa categoria. Talvez nos textos de seus pupilos essa exaltação seja mais claramente observada.

Vale ressaltar que embora a Antroposofia seja oriunda da Teosofia, essa origem não apareceu explícita nos textos; mesmo na obra intitulada Teosofia, onde Steiner fala sobre a própria Teosofia. Isso se dá pela preocupação ativa que Steiner teve em minimizar aberturas para a identificação da Antroposofia como um ramo da Teosofia ${ }^{55}$.

\footnotetext{
${ }^{53}$ Benthall, Returning to religion, 28-32.

${ }^{54}$ Benthall, Returning to religion, 32-33.

${ }^{55}$ Clemen, "Anthroposophy”, 281.
} 


\section{Experiências de conversão}

Embora observável mais explicitamente nas religiões abertamente proselitistas, a experiência de conversão é um aspecto integral das religiões ${ }^{56}$. Três aspectos centrais à conversão podem ser citados: (1) a mudança de um sistema de crenças para outro, (2) a mudança de ações sociais, justificadas pelo novo sistema de crenças adotado, e (3) a mudança das pessoas que operam e controlam o sistema de crenças ${ }^{57}$.

Embora sejam estimuladas mudanças de ações e a adoção de um novo sistema de crenças nos livros, essa categoria não foi objetivamente notada no material analisado. Como para Steiner muitos são os caminhos possíveis que conduzem à libertação espiritual, não fica tão evidente o caráter proselitista esperado dessa categoria.

\section{Aceitação do paradoxo doutrinal}

Para Benthall, toda religião é paradoxal, aceitando a existência de ideias que contrariam a lógica, mas que soam perfeitamente plausíveis àqueles que nelas creem. Em alguns casos há paradoxos na própria narrativa sagrada. Citando o exemplo bíblico, Deus é descrito como onisciente, o que pressupõe o conhecimento do destino de todos. Todavia, com o livre arbítrio o pressuposto é outro: as pessoas são livres para seguir os caminhos de Deus, e assim fazerem parte do plano divino. Mas se Deus já sabe de antemão quem será salvo ou não, qual o propósito de termos o livre arbítrio $?^{58}$

Devido à complexidade da categoria, que requer um olhar mais aprofundado, não foram observados indícios concretos de paradoxos doutrinais na literatura. Os poucos trechos que poderiam intuir a isso eram vagos, e demandariam postura interpretativa que extrapola a metodologia adotada.

\section{Cerimônias e rituais}

O rito religioso representa o pulsar vital da maioria das religiões, ao ponto de diversos antropólogos classificarem-no como uma das partes constituintes da religião ${ }^{59}$. Para Benthall, a categoria cerimônia e rituais diz respeito a formalidades, palavras, música, dança, meditações e outros movimentos corporais, usualmente repetitivos, com capacidade de reafirmar ou renovar um conjunto de valores simbólicos específico ${ }^{60}$.

Foram encontrados inúmeros indícios de rituais nos livros A Ciência Oculta, A educação prática do pensamento, $O$ conhecimento dos mundos superiores, e Economia viva, descritos como práticas que auxiliariam o encontro com o "eu" (self). Aqui elencamos os dois que apareceram com maior frequência.

\footnotetext{
${ }^{56}$ Benthall, Returning to religion, 33-35.

${ }^{57}$ Benthall, Returning to religion, 34.

${ }^{58}$ Benthall, Returning to religion, 35-38.

${ }^{59}$ Silas Guerriero, “Antropologia da religião”, in Compêndio de Ciência da Religião, org. João Décio Passos e Frank Usarski (São Paulo: Paulinas, Paulus, 2013), 252-253.

${ }^{60}$ Benthall, Returning to religion, 38-40.
} 
Auto-observação: Prática que consiste na auto-observação das próprias respostas frente a estímulos externos, buscando superar o automatismo comportamental. Em $A$ Ciência Oculta Steiner considera que a auto-observação é o primeiro passo para a percepção da alma. Tanto nessa obra quanto em $O$ conhecimento dos mundos superiores há exemplos de rituais visando à promoção dessa auto-observação.

Estudos das representações simbólicas: Ao nos depararmos com a magnificência da natureza, devemos transpor sua forma, compreendendo em cada coisa uma manifestação da criação, através de um arcabouço simbólico de uma percepção profunda e complexa de evolução que mostra toda a sua transformação em ciclos infinitos de morte e vida. Steiner diz que "o essencial não é $o$ que se representa; importante é que, pelo modo de representação, o elemento representativo liberta o anímico de qualquer dependência do físico" "61. Essas representações não tem o intuito de reproduzir algo exterior, mas atuar diretamente na alma, despertando-a.

\section{Acalento frente à morte}

A morte, embora inevitável, é um grande tabu nas sociedades. Como quem morre não pode, objetivamente, voltar para relatar como é essa experiência, há uma aura de mistério muito forte no ato de morrer. Com isso, a terminalidade pode ser concebida como um escuro que precede o final, onde nada mais existe para ser alcançado. Esse vazio inflama um medo que se agarra em uma explicação a ser subsidiada pelas religiões, buscando nos acalentar para essa terrível certeza ${ }^{62}$.

Encontraram-se indícios de acalento frente à morte em todos os livros, exceto Economia viva e $A$ educação prática do pensamento. $\mathrm{O}$ discurso antroposófico diz que a morte é a expressão do mundo suprassensorial chegando a um ponto que não pode mais avançar. Com isso, a vida se desprende, desabrochando ao novo. Os humanos carregam o que remanesceu de sua existência passada, e dentro desse envoltório se forma o germe daqueles que viverão futuramente. Portanto, seríamos seres ao mesmo tempo de natureza mortal e imortal. Na morte, o elemento mortal está em seu fim, e o imortal em seu início. Nossa missão é buscar na mortalidade o fruto para o imortal.

Em $O$ conhecimento dos mundos superiores, Steiner declara que quando alguém se torna discípulo da Ciência Oculta, fazendo dela uma prática diária, é promovido um entendimento de que os elementos de um mundo em perecimento estão contidos no todo. Seguindo aos poucos o caminho da Antroposofia, seria possível quebrar o poder decadente desse mundo, suplantando-o com elementos imortais revitalizados.

Em $O$ anjo em nosso corpo astral é comentado que "[...] a alma humana continua a desenvolver-se, mesmo após ter atravessado o portal da morte. Essa alma [...] cresce em suas forças do intelecto mesmo depois desta [vida], aprendendo cada vez mais a

\footnotetext{
${ }^{61}$ Steiner, A ciência oculta, 223.

${ }^{62}$ Benthall, Returning to religion, 40-42.
} 
compreender" ${ }^{\prime 63}$. Essa citação é um acalento ao sentimento iminente de não existir, ao revelar que após a morte descansaremos da árdua existência material, ao mesmo tempo em que poderemos continuar nossa ascensão espiritual em Cristo.

Em A Ciência Oculta o Mistério de Gólgota é usado para explicar o após-morte:

Desde então, ao cruzar o umbral da morte o homem pode levar consigo aquilo que o liberta da solidão no mundo espiritual. [...] E uma vez consumado o "Mistério de Gólgota", uma vez sofrida a morte na cruz, o Cristo apareceu no mundo onde as almas permanecem após a morte $[\ldots]^{64}$.

Gólgota é o nome do monte onde Jesus foi crucificado. O Mistério de Gólgota, então, envolve todos os aspectos simbólicos do momento da crucificação e do derramar do sangue de Cristo na terra. É, para o esoterismo cristão, um dos acontecimentos mais importantes da humanidade, algo que poucos conseguem realmente compreender. Essa citação se apresenta como um acalento ao garantir o reencontro com Jesus Cristo não apenas no além-vida, mas também simboliza a morte em vida para renascer na consciência crística, visando o encontro com o Cristo interno.

\section{Martírio}

O martírio é um tema frequente nas religiões. Mártires são pessoas que morrem pela fé, defendendo ferozmente, até o último suspiro, suas convicções religiosas, para preservar a essência da verdade acreditada, propagando-a às gerações futuras. A etimologia de "mártir" deriva do grego $\mu \alpha ́ \rho \tau v \rho ~(m a ́ r t u r)$, literalmente "testemunha". Nesse sentido, mártires são testemunhas de um plano histórico de cunho religioso, e por seu sofrimento, seus ideais alcançam proporções grandiosas ${ }^{65}$.

Foram encontrados indícios de martírio em cinco livros: A missão das almas dos povos, Teosofia, Economia e sociedade à luz da Ciência Espiritual, O anjo em nosso corpo astral e $O$ conhecimento dos mundos superiores. O martírio na Antroposofia é visto como algo positivo, pois se crê que algumas benesses só podem ser alcançadas pelo autossacrifício. Esse sacrifício é alegórico, mediante transformações que purificam o espírito das vontades terrenas: apego, egoísmo, desejos e prazeres. A cada instante os humanos necessitam sacrificar "o que são" em nome daquilo que "podem vir a ser".

Ao comentar sobre os saberes adquiridos pela meditação, Steiner diz que "[...] seu trabalho, seu sofrimento cabem-lhe por motivos que tocam as grandes leis espirituais do Universo"66 . Essa explicação demonstra a valorização do martírio.

\footnotetext{
${ }^{63}$ Steiner, $O$ anjo em nosso corpo astral, 40.

${ }^{64}$ Steiner, A ciência oculta, 212.

${ }^{65}$ Benthall, Returning to religion, 42-43.

${ }^{66}$ Steiner, O conhecimento dos mundos superiores, 30.
} 
$\mathrm{Na}$ obra Teosofia, outro forte indício de martírio é encontrado: “[...] o dever é superior ao prazer e desprazer; pode, alias, situar-se tão alto para o homem que ele lhe sacrifique a vida"67. Esse sacrifício é visto como uma chama imperecível que queima os desejos mundanos, transmutando-os naquilo que seria da natureza do "eu" (self). O discípulo se sobrepõe à alma da sensação, dominando-a ao invés de se deixar dominar por ela. Mas esse processo é visto, na literatura êmica, como oposto ao prazer.

\section{Explicação da origem do mal}

O porquê do mal é uma questão central a diversas religiões, que buscam sanar a angústia advinda de sua existência. Usualmente as explicações da origem do mal buscam apresentar fundamentos e mitologias que abarquem o propósito da crueldade e do sofrimento humano na ordem cósmica ${ }^{68}$.

Foram encontrados vestígios de explicação para o mal nas obras Filosofia da Liberdade, A Ciência Oculta, A missão das almas dos povos, Teosogia e Economia e sociedade à luz da Ciência Espiritual. Esse tema é muito complexo, espalhando-se por diversos motivos. Por isso, elencamos as citações que apresentam as ideias que aparecem com maior frequência na literatura êmica.

A Ciência Oculta é o livro que possui melhores passagens que exemplificariam essa categoria. Em uma delas, Steiner apresenta uma origem do mal em um mito que justifica a existência do egoísmo na humanidade:

[...] seres espirituais inferiores, que não podiam acompanhar a evolução terrestre regular e, portanto, faziam-lhe oposição. Esses influenciavam continuamente os homens, de modo a inspirar-lhes interesses verdadeiramente contrários ao bem da humanidade [...] A consequência foi uma grande corrupção da humanidade. $\mathrm{O}$ mal se difundiu cada vez mais $[\ldots]^{69}$.

O que ou quem são esses seres não fica evidente nas obras, mas Steiner comenta que em um passado remoto esses seres inferiores estabeleceram domínio significativo sobre a humanidade. Esse controle teria levado os humanos a exercerem cegamente ações opostas ao crescimento e ao amor, gerando as tentações, que seduzem não apenas os indivíduos comuns, mas também uma parcela dos iniciados na Ciência Espiritual.

Na mesma obra, outro exemplo é encontrado:

[...] quando o eu cobiça um prazer que serve ao seu ser não para a conservação e o desenvolvimento, mais para a destruição, tal cobiça não pode ser efeito nem da atuação de seus três corpos nem de sua própria natureza, mas apenas daquelas

\footnotetext{
${ }^{67}$ Steiner, Teosofia, 38.

${ }^{68}$ Benthall, Returning to religion, 43-44.

${ }^{69}$ Steiner, A ciência oculta, 193-194.
} 
entidades que, quanto à sua verdadeira forma, permanecem oculta aos sentidos mas podem, justamente, aproximar-se da natureza superior do eu e despertar-lhe apetites não relacionados com o mundo sensório, embora satisfazíveis apenas por meio deste. Existem, de fato, seres que têm por alimento paixões e cobiças piores do que todos os apetites animais, pois não se realizam no mundo sensível, e sim se apoderam do espírito e atraem-no para o campo inferior dos sentidos [...] as forças destruidoras desses seres ultrapassam em medida incomensurável toda a fúria devastadora que existe no mundo animal sensorialmente perceptível ${ }^{70}$.

Essa personificação dos prazeres mundanos é um exemplo claro dessa categoria.

\section{Altruísmo}

Quase todo sistema religioso prega o altruísmo, incorporado no reconhecimento das necessidades dos outros, colocadas além do interesse próprio. Citando alguns casos, temos frases como "amar o próximo como a si mesmo" (Cristianismo), "evitar todo o mal, cultivar o bem e purificar a mente" (Budismo), e "nenhum de vocês crê verdadeiramente até que ame para o seu irmão o que ama para si mesmo" (Islã) $)^{71}$.

Vestígios de altruísmo foram encontrados em Filosofia da liberdade, Teosofia, Economia e sociedade à luz da Ciência Espiritual, Economia viva e $O$ conhecimento dos mundos superiores. No livro Economia e sociedade à luz da Ciência Espiritual, são valorizadas "[...] as virtudes do trabalho abnegado e da atuação em favor da comunidade",72. Em $O$ conhecimento dos mundos superiores Steiner reforça esse entendimento pela negativa, ao dizer que "quem procura algo somente para si, enquanto o fizer não encontrará absolutamente nada da parte dos ocultistas" $"$.

$\mathrm{Na}$ Antroposofia, acredita-se que desejos egoístas conduzem a humanidade à autodestruição, promovendo miséria e penúria. Para conseguir alimentar a humanidade sem escassez, devemos semear a beneficência. Esse trabalho deve estar em harmonia com o todo, sem exigir para si o resultado direto deste. Os frutos devem, de preferência, ser distribuídos em benefício da humanidade, pois se todos fizerem isso, nossa nutrição será advinda da semeadura dos demais, em uma rede fraterna de sustento universal.

\section{Interiorização de um código moral}

Benthall comenta que a interiorização de um código moral ocorre quando determinados preceitos se tornam tão íntimos que são incorporados nas suas condutas de quem os segue, naturalizando-se ${ }^{74}$. A dimensão do ethos religioso é, para Geertz ${ }^{75}$, um dos

\footnotetext{
${ }^{70}$ Steiner, A ciência oculta, 82-83.

${ }^{71}$ Benthall, Returning to Religion, 44-46.

${ }_{72}$ Steiner, Economia e sociedade à luz da Ciência Espiritual, 24.

${ }^{73}$ Steiner, O conhecimento dos mundos superiores, 148.

${ }^{74}$ Benthall, Returning to Religion, 46-47.

${ }^{75}$ Cliford Geertz, A interpretação das culturas (Rio de Janeiro: LTC, 2008).
} 
constituintes básicos da religião, reforçando a importância dessa categoria na identificação de um objeto como sendo religioso.

Foram encontrados indícios nas obras A Ciência Oculta, Filosofia da liberdade, A missão das almas dos povos, Economia e sociedade à luz da Ciência Espiritual, Economia viva e $O$ anjo em nosso corpo astral. Pela grande diversidade de códigos morais encontrados, destacamos apenas os quatro mais citados.

Agir através da bondade do coração: Em A Ciência Oculta é apresentado que a alegria é efềmera. Para que a alegria se transforme em felicidade, devemos agir através da bondade do coração. Segundo Steiner, "um ato executado por bondade do coração é um ato cujo autor não age em seu próprio interesse, e sim no interesse de seu semelhante. Tal ação pode ser denominada moralmente boa"76. O indício de que a bondade do coração está instaurada é observado quando uma alma "absorve" o interesse de outra alma, convertendoo em seu próprio interesse.

Paciência e perseverança: Os exercícios antroposóficos são árduos - não no sentido de serem difíceis ou complexos, mas por serem práticas que devem ser aplicadas em todas as ações e relações da vida do iniciado. Por isso, Steiner diz que "duas coisas são inerentes à disciplina espiritual: a paciência e a perseverança" "77. O indivíduo que não desperta em si essas qualidades não alcançará muita coisa na Antroposofia.

Amar a todas as coisas: Segundo a Antroposofia, somos alienados, não nos permitindo conectar-nos com a essência do meio. Mas se deixássemos nossa parte infindável, o "eu" (self), conduzir-nos, os corpos mortais seriam apenas mediadores, revelando o eterno das coisas. Ao dirigir nosso espírito ao eterno nos tornaríamos harmoniosamente presentes, unificando nossa essência ao nosso meio. Assim, aprenderíamos a valorizar o mundo, promovendo o amor, que passaria a fluir ao todo. No livro Teosofia, é dito que o propósito disso é nos ensinar a amar a própria existência.

Falara a verdadela força do verbo: Steiner enxerga a palavra como uma dança eurrítmica que desabrocha vários entendimentos que se deve respeitar, pois todo ponto de vista é a vista de um ponto. A necessidade de conscientização, frente à compreensão de que a palavra em desalinho com as ações e pensamentos é vazia, fica muito evidente em $O$ anjo em nosso corpo astral. $\mathrm{O}$ verbo, logos, só é devidamente compreendido se alinhado a todos os corpos, atingindo a essência do ser. A ação do verbo, sua força e criação, só poderá ser compreendida quando o logos for novamente unido a Cristo.

\section{Sectarismo}

A história das religiões é marcada pelo sectarismo, que esculpe relações de discordância que podem levar à intransigência e intolerância. Este posicionamento é

\footnotetext{
${ }^{76}$ Steiner, A ciência oculta, 228.

${ }^{77}$ Steiner, A ciência oculta, 229.
} 
construído a partir de ideias rígidas de defesa das doutrinas, traduzindo a existência do mundo em uma visão binária: "nós" e "eles"78.

Foram encontrados indícios de sectarismos em $O$ conhecimento dos mundos superiores, Economia viva e Economia e sociedade à luz da Ciência Espiritual. O sectarismo aparece quando Steiner adverte os que não seguem os ensinamentos de que "[...] o mundo purificado se desenvolverá para além de ti. Tu serás excluído dele. Assim, tua senda será negra, ao passo que aqueles de quem te separaste seguirão a senda branca" ${ }^{, 79}$. No contexto desse recorte, os indivíduos já desvelados do primeiro grau do mundo suprassensorial terão que trabalhar para conduzir também seus semelhantes na senda esotérica. Somente assim o portal para o mundo superior será aberto. Se há a necessidade de conduzir alguém e outros ficarão para trás, há aqui uma noção de "nós" e "eles".

Steiner novamente distingue "nós" e "eles" ao dizer que "tal fato não pode ser 'provado' a um desconhecedor da Ciência Espiritual”. O fato da citação se refere ao entendimento de que a Ciência Espiritual só poderá ser compreendida quando a semente interna desabrochar em uma fonte espiritual, que deverá penetrar todas as esferas de nossas vidas. Mas se somente quem conhece a Ciência Espiritual tem acesso a tais "provas", então existe aqui também uma dimensão do "nós" diferenciada do "eles".

\section{Identidade política}

A identidade é o reconhecimento que um indivíduo tem de si próprio. Ao tratar de identidade política, Benthall considera que ela se insere no conjunto de caracteres que abarca a identidade como um todo: etnia, classe, gênero, idade, linguagem e ideologia política $^{80}$. É importante essa distinção porque há grande divergência, entre os cientistas da religião, sobre a questão da identidade política. Contudo, as diferentes vertentes tendem a convergir a um ponto: a religião nunca é o único fator determinante na construção da identidade política de um grupo religioso.

Nas obras da Antroposofia, foram encontrados indícios de identidade política em $O$ anjo em nosso corpo astral, Economia viva, Economia e sociedade à luz da Ciência Espiritual, O conhecimento dos mundos superiores, Filosofia da liberdade e A missão das almas dos povos. O livro $A$ missão das almas dos povos talvez seja o que mais apresentou isso, visto defender uma teoria -muito controversa mesmo entre os próprios antroposóficos $^{81}$ - de que não existem etnias, mas sim "almas de povos", que evoluem separadamente. A existência de diferentes etnias aconteceria porque na evolução

\footnotetext{
${ }_{78}^{78}$ Benthall, Returning to religion, 47-50.

${ }^{79}$ Steiner, O conhecimento dos mundos superiores, 146 [grifo nosso].

${ }^{80}$ Benthall, Returning to religion, 50-51.

81 Peter Staudenmaier, "Race and redemption: racial and ethnic evolution in Rudoulf Steiner's Anthroposophy”, Nova Religio XI, no. 3 (2008): 5.
} 
hierárquica há "atrasos" de alguns povos, que precisam evoluir em uma perspectiva distinta à das almas que estão no estágio evolutivo "normal".

Essa é uma noção eivada pelo imaginário que dominava a Alemanha no fim do século XIX e início do século XX, influenciada pelo darwinismo social (maiores considerações são encontradas em textos de Staudenmaier ${ }^{82,83}$ ). É clara a influência dessa visão em uma das falas de Steiner:

Por exemplo, na região onde agora desenvolvemos particularmente nossa atividade científico-espiritual, isto é, na Alemanha, temos visto, através de séculos, o embate do Arcanjo dos alemães ao encontrar a ação dos Espíritos da Personalidade às vezes conflitantes. O conflito entre os Espíritos anormais da Personalidade e o Arcanjo manifestam-se na prolongada desunião de toda a nação alemã, formando todos esses pequenos países pseudo-étnicos ${ }^{84}$.

Considerar que outros países germânicos são pseudoétnicos é uma perspectiva baseada, centralmente, na identidade política de Steiner. O que levaria a Holanda, por exemplo, a ser considerada "pseudoétnica", e a Alemanha não? Seriam as fronteiras de uma nação simplesmente pautadas em etnia? Onde ficam as diferenças culturais, políticas, filosóficas e econômicas? A literatura êmica analisada não parece dar conta de responder a essas perguntas.

\section{Distinção entre o sagrado e o profano}

A distinção entre o sagrado e o profano, conceito ético que Benthall adotou de Durkheim, explica como objetos mundanos, quando submetidos a determinados rituais ou celebrações, tornam-se consagrados, sendo excluídos do mundo comum e assumindo uma função distinta na comunidade. Reflete também o insignificante para o ser religioso, com o sagrado sendo tudo o que importa de um modo especial. Essa distinção é notada particularmente através de rituais e atitudes cotidianas ${ }^{85}$.

É importante citar que, enquanto categoria ética, essa distinção não foi encontrada objetivamente nos textos êmicos selecionados. Contudo, acreditamos que essa distinção ocorra nas comunidades de adeptos. Estudos de campo para checar sua presença tornariam mais claros sua ocorrência entre os antroposóficos.

\section{Estados extáticos de consciência}

Também chamados de estado de transe, os estados extáticos de consciência são estados de percepção que diferem do nível de consciência cotidiano. Dentro de uma crença

\footnotetext{
${ }^{82}$ Staudenmaier, Between Occultism and Nazism, 1-412.

${ }^{83}$ Staudenmaier, "Race and redemption", 4-36.

${ }^{84}$ Steiner, A missão das almas dos povos, 33, grifo nosso.

${ }^{85}$ Benthall, Returning to religion, 51-52.
} 
religiosa, esses estados são provocados pela força mobilizadora dos rituais, e usualmente estão relacionados a sentimentos catárticos de euforia e perda de controle ${ }^{86}$.

Foram encontrados indícios dessa categoria em apenas dois livros: $O$ conhecimento dos mundos superiores e A Ciência Oculta. Boa parte da forma como o êxtase é apresentado na Antroposofia deriva da ideia de canalização, a convicção de que podemos receber informações de outras fontes além de nossa consciência normal. Essas informações seriam canalizadas de entidades ou sabedorias que vivem nos mais diversos níveis de realidade. A canalização ocorre em diversos graus de alteração da consciência, desde um transe total, um completo estado de dissociação da realidade, a um distanciamento leve da consciência por parte do canalizador, para que se abra o canal para receber a informação revelada $^{87}$.

Para Hanegraaff, a canalização é um constituinte da Nova Era ${ }^{88}$, movimento posterior à Antroposofia. Mas em sua tese Hanegraaff apresenta a Nova Era como uma forma secularizada dos esoterismos ocidentais ${ }^{89}$. Possuindo a Antroposofia uma fonte esotérica assumida, podemos considerar que não é surpresa autores como McDermott citarem a canalização como uma parte constituinte da vivência antroposófica ${ }^{90}$.

$\mathrm{Na}$ literatura analisada, indícios de canalização aparecem na seguinte fala:

O discípulo deve tomar como ponto de partida os textos que por si brotam de tal revelação na meditação. Na literatura mística, na gnóstica, na científico-espiritual, encontrará tais textos. Aí se lhe apresentam os assuntos para sua meditação. Os próprios pesquisadores espirituais registraram pensamentos da ciência divina em tais textos; o Espirito, através de seus mensageiros, fê-los anunciar ao mundo ${ }^{91}$.

É claro o processo de canalização nesse exemplo porque é o próprio "eu” (self), que no caso está sendo entendido como algo distinto da consciência cotidiana comum, quem dita essas revelações através da meditação.

Outro caso evidente que pode ser ressaltado é o seguinte:

Por causa de seu corpo astral mais influenciado pelo princípio luciférico, deviam passar por uma disciplina mais severa, podendo então, num estado menos incorpóreo do que os demais, receber não a manifestação revelado do próprio Cristo, mas de outros seres superiores ${ }^{92}$.

\footnotetext{
${ }^{86}$ Benthall, Returning to religion, 53-54.

${ }^{87}$ Hanegraaff, New Age Religion and Western Culture, 23-34.

${ }^{88}$ Hanegraaff, New Age Religion and Western Culture, 23-34.

${ }^{89}$ Hanegraaff, New Age Religion and Western Culture, 411-513.

${ }^{90}$ McDermott, "Anthroposophy”, 392.

${ }^{91}$ Steiner, O conhecimento dos mundos superiores, 30 [grifo nosso].

${ }^{92}$ Steiner, A ciência oculta, 191 [grifo nosso].
} 


\section{Missionarismo}

O missionarismo é uma característica importante das religiões, em especial das que competem por um mercado religioso não regulado, como no caso brasileiro. Missionários são pessoas incumbidas de realizar a propagação de sua fé, que recebem missões de proselitismo das quais se sentem honrados em realizar, dedicando-se a pregar seus ideais em locais onde sua crença ainda não foi difundida. Assim, exercem um trabalho de promoção social (propaganda) ou de revitalização de sua religião ${ }^{93}$.

Foram encontrados indícios de missionarismo em duas obras: $O$ conhecimento dos mundos superiores e Teosofia.

Na primeira delas, Steiner diz:

Até agora liberastes apenas a ti mesmo; agora, como alguém livre, poderás libertar todos os teus semelhantes no mundo sensorial. Até hoje, te esforçaste como indivíduo; agora, incorpora-te ao todo, para não trazeres apenas a ti mesmo ao mundo suprassensorial, mas também tudo o mais que no mundo sensorial ${ }^{94}$.

Para o discurso êmico, a elevada missão de se libertar do manto espesso que resguarda o mundo suprassensorial deve ir além do despir-se de si próprio. $O$ indivíduo liberto deverá, com bravura, semear em outros campos a capacidade do serviço realizado nele mesmo, facilitando também o desabrochar de seus semelhantes. Sua oração deve irradiar para que todos os seres humanos possam alcançar o sentido proposto pela Antroposofia.

Na segunda obra, é encontrada a seguinte afirmação sobre a humanidade:

Mas o observador do supra-sensível não deve falar somente aos investigadores do mundo espiritual. Ele deve dirigir-se a todos os homens, pois é seu mister informar sobre coisas que interessam a todos os homens. Ele sabe, aliás, que ninguém pode ser um "homem" na plena acepção do termo sem um conhecimento dessas coisas; e fala a todos os homens porque sabe existirem vários graus de entendimento da sua mensagem $^{95}$.

Essa preocupação em difundir os ensinamentos antroposóficos visando auxiliar toda a humanidade a alcançar o estado de consciência desejado pela Antroposofia é confirmada pelo trecho supracitado.

\footnotetext{
${ }^{93}$ Benthall, Returning to religion, 54-55.

${ }^{94}$ Steiner, O conhecimento dos mundos superiores, 146 [grifo nosso].

${ }^{95}$ Steiner, Teosofia, 20 [grifo nosso].
} 


\section{Tradição}

Tradição e religião se misturam em um entrelaçar que busca um fundamento e legitimação no passado, na passagem de costumes, crenças, lendas e ritos. Embora a tradição seja transformada, o sentimento que evoca é de atemporalidade, justificando atitudes e comportamentos dentro do grupo ${ }^{96}$.

Foi verificado indícios dessa categoria em $O$ conhecimento dos mundos superiores, A Ciência Oculta, Filosofia da liberdade, Economia viva e $O$ anjo em nosso corpo astral. Os livros analisados evocam heranças de civilizações míticas antigas (p. ex. Lemúria e Atlântida), em um contínuo perpetuo de influências ancestrais.

Uma passagem que demonstra isso diz que:

Na literatura pertinente encontram-se, de certa forma, alusões à época da evolução humana anterior à atlântica. Denomina-se época lemúrica da Terra [grifo nosso] aquela à qual se seguiu a atlântica. Por outro lado, a época em que as forças lunares ainda não haviam produzido seus efeitos principais pode ser chamada de hiperbórea. Essa é ainda precedida por outra, que coincide com os primórdios da evolução física terrestre. Na tradição bíblica, a época anterior à intervenção luciférica é descrita como a época paradisíaca, e a decida dos homens à Terra e sua integração no mundo físico como expulsão do Paraíso ${ }^{97}$.

Para Steiner, desde a criação do planeta há povos na Terra. Os seres que nele habitavam começaram como formas espirituais, e foram progredindo por diversos estágios com várias influências, inclusive dos astros, até alcançarem a forma atual. Por essa visão, estaríamos vivendo o período Pós-Atlântico.

\section{Conclusões}

Foi verificado o caso da Antroposofia, que não se identifica explicitamente como um campo religioso, mas que conforme o referencial teórico adotado se enquadrar nos conceitos acadêmicos do que é uma religião. Foi adotada, com isso, a hipótese de que a Antroposofia poderia ser um exemplo de religião implícita. Aplicando a metodologia de Benthall, foi feito um levantamento dos livros indicamos como basilares por uma associação antroposófica brasileira para entender a Antroposofia, escritos por seu próprio fundador, o austríaco Rudolf Steiner.

Ao término desse estudo, nossa hipótese se demonstrou verdadeira. Das dezenove categorias previstas pelo método analítico de Benthall, foram encontrados indícios de quinze delas na literatura êmica estudada, e não se descarta a possibilidade de que as quatro

\footnotetext{
${ }^{96}$ Benthall, Returning to religion, 55.

${ }^{97}$ Steiner, A ciência oculta, 188-189 [grifo nosso].
} 
categorias não observadas estejam presentes em outras obras antroposóficas que não foram analisadas nessa pesquisa.

Visto a natureza qualitativa desse estudo, sugere-se a repetição do mesmo estudo, utilizando o mesmo parâmetro de análise para confirmação. Além disso, para avaliar se a hipótese destacada no parágrafo anterior, de fato, confirma-se, seria interessante aplicar o mesmo método também em obras que não entraram no escopo do presente estudo, como as obras dos discípulos de Steiner, por exemplo.

\section{Referências}

Benthall, Jonathan. Returning to religion: why a secular age is haunted by faith. London: I. B. Tauris, 2008.

Clemen, Carl. “Anthroposophy”. The Journal of Religion IV, no. 3 (1924): 281-292.

Cruz, Eduardo R. "Estatuto epistemológico da Ciência da Religião". Ciberteologia: Revista de Religião e Cultura X, no. 47 (2014): 67-80.

Geertz, Cliford. A interpretação das culturas. Rio de Janeiro: LTC, 2008.

Gil, Antonio Carlos. Métodos e técnicas de pesquisa social. $6^{\mathrm{a}}$ ed. São Paulo: Atlas, 2008.

Guerriero, Silas. "Antropologia da religião". In Compêndio de Ciência da Religião.

Organizado por João Décio Passos e Frank Usarski. São Paulo: Paulus, 2013.

Hanegraaff, Wouter J. "Defining religion in spite of History". In The Pragmatics of Defining Religion: Contexts, Concepts \& Contests. Edited by Jan G. Platvoet and Arie L. Molendijk. Leiden: Brill, 1999.

Hanegraaff, Wouter J. New Age Religion and Western Culture: Esotericism in the Mirror of Secular Thought. Leiden: Brill, 1996.

Hock, Klaus. Introdução à Ciência da Religião. São Paulo: Loyola, 2010.

Leijenhorst, Cees. "Anthroposophy". In Dictionary of Gnosis \& Western Esotericism. Edited by Wouter J. Hanegraaff. Leiden: Brill, 2006.

McDermott, Robert A. "Anthroposophy". In Encyclopedia of Religion. Edited by Lindsay Jones. Farmington: Thomson Gale, 2005.

Nesti, Arnaldo. “Implicit Religion”. In Encyclopedia of Religion. Edited by Lindsay Jones. Farmington: Thomson Gale, 2005.

Pasi, Marco. "Theosophy and Anthroposophy in Italy during the First Half of the Twentieth Century”. Theosophical History: A Quartely Journal of Research XVI, no. 2 (2012): 81-119.

Staudenmaier, Peter. Between Occultism and Nazism: Anthroposophy and the Politics of Race in the Fascist Era. Leiden: Brill, 2014.

Staudenmaier, Peter. Race and redemption: racial and ethnic evolution in Rudoulf Steiner's Anthroposophy. Nova Religio XI, no. 3 (2008): 4-36. 
Toncheva, Svetoslava. "Antroposophy as Religious Syncretism". SOTER: Journal of Religious Science XLVIII (2013): 81-89.

Usarski, Frank. "História da Ciência da Religião". Ciberteologia: Revista de Religião e Cultura X, no. 47 (2014): 139-150.

Wallace, Anthony F. C. Religion: an Anthropological View. New York: Random House, 1966.

\section{Literatura êmica analisada}

Steiner, Rudolf. A Ciência Oculta: esboço de uma cosmovisão supra-sensorial. São Paulo: Antroposófica, 2001.

Steiner, Rudolf. A educação prática do pensamento: aprender a pensar a partir da realidade. São Paulo: Antroposófica, 2010.

Steiner, Rudolf. A missão das almas dos povos. São Paulo: Antroposófica, 2014.

Steiner, Rudolf. Economia e sociedade à luz da Ciência Espiritual. São Paulo: Antroposófica, 2007.

Steiner, Rudolf. Economia viva: o mundo como organismo econômico único. São Paulo: Antroposófica, 2006.

Steiner, Rudolf. Filosofia da liberdade: fundamentos para uma filosofia moderna. São Paulo: Antroposófica, 2008.

Steiner, Rudolf. $O$ anjo em nosso corpo astral: como eu encontro Cristo? São Paulo: Antroposófica, 2008.

Steiner, Rudolf. O conhecimento dos mundos superiores. São Paulo: Antroposófica, 2011.

Steiner, Rudolf. Teosofia: introdução ao conhecimento supra-sensivel do mundo e do destino humano. São Paulo: Antroposófica, 1994.

\section{Outras fontes primárias}

Setzer, Valdemar W. "O que é Antroposofia" (1999 [acesso em 19 de abril de 2016]): http://www.sab.org.br/antrop/ANmainFrame.htm

Wachsmuth, Gunter. The Life and Work of Rudolf Steiner: From the Turn of the Century to his Death. New York: Whittler, 1955.

Yeager, Jean. "Is Antroposophy a religion?" Em Waldorf Answer (2004-2014 [acesso em 12 de março de 2016]): http://www.waldorfanswers.org/NotReligion1.htm 